\title{
16
}

\section{Modeling Sedimentation in Stormwater Storage Facilities}

\author{
John N. MacKenzie
}

\begin{abstract}
Alberta Environment has implemented stormwater quality enhancement requirements for all new development areas in Calgary draining to the Bow River system. Current criteria are expressed in terms of reduction in total suspended solids (TSS) prior to discharge. To date in Calgary the assessment of stormwater quality enhancement has been assessed by continuous simulation using the QHM model.

This chapter presents a review and summary of the technical approach to date in assessing the degree of TSS removal provided by a stormwater storage facility. The current interpretation of total suspended solids with reference to street sweeping sampling is examined and the effect of short-circuiting on TSS removal in a stormwater storage facility is assessed. Suggestions are made to clarify the definition of TSS related to street sweeping sampling and to modify the QHM simulation of stormwater storage facilities to address short-circuiting effects.
\end{abstract}

\subsection{Introduction}

Past design of storm drainage systems has often assumed that stormwater is not significantly contaminated with respect to the assimilation capacity of receiving waters. Under this assumption stormwater has been discharged

\footnotetext{
MacKenzie, J. 2003. "Modeling Sedimentation in Stormwater Storage Facilities." Journal of Water Management Modeling R215-16. doi: 10.14796/JWMM.R215-16.

(C) CHI 2003 www.chijournal.org ISSN: 2292-6062 (Formerly in Practical Modeling of Urban Water Systems. ISBN: 0-9683681-7-4)
} 
directly to the nearest watercourse without stormwater quality enhancement treatment. Recently, however, it has generally been recognized that direct discharge of stormwater can have detrimental effects on receiving waters related to the water quality of the stormwater runoff as well as the rate and/or volume of stormwater runoff.

Alberta Environment and the City of Calgary now recognize the potential for significant input of pollutants from stormwater runoff. Stormwater runoff, particularly after a prolonged period without rainfall, can be contaminated through contact with street litter, eroded swales, de-icing chemicals, animal droppings, traffic residues, fertilizers, biocides and atmospheric dustfall. Major constituents of street runoff (organic matter, algal nutrients, coliform bacteria, heavy metals and pesticides) have been found in the form of suspended solids.

Alberta Environment has imposed stormwater quality enhancement requirements for any new development that will drain to the Bow River system in Alberta. At present, 2002, these requirements are interim, and are expressed in terms of removal of $85 \%$ of the sediment washoff from a new development area prior to discharge, expressed as $85 \%$ removal of TSS. One can postulate that the stormwater quality enhancement requirements will become more stringent in the future in terms of suspended solids removal. Further, there is a reasonable probability that the stormwater quality enhancement requirements may be expressed in the future in terms of specific pollutant removals, for example nutrients (phosphorous and/or nitrogen expressed in a specific chemical state).

To increase stormwater quality enhancement, discharge from a sedimentation facility can be routed to a constructed wetland. Particulate settling and filtration and bacterial decay will remove a large portion of the remaining particulate contaminants and bacteria in the stormwater runoff. In addition, biological processes (e.g. plant uptake) and adsorption to soils will remove a portion of the soluble contaminates from the stormwater runoff at least in the short term.

If a sedimentation facility and wetland are used in series, often referred to as a treatment train, the operation of the sedimentation facility to protect the subsequent wetland facility by removing mass loadings from the stormwater runoff is particularly important.

This chapter presents a potentially more realistic application of an existing computer simulation model for sedimentation in stormwater storage facilities to improve the accuracy of the model. The calculations are intended to be illustrative of the suggested technique, not real sedimentation. 


\subsection{Computer Simulation Methodology}

\subsubsection{Runoff and Pollutant Simulation}

The technical analyses to size sedimentation facilities are based on a continuous simulation modeling approach. This approach allows a continuous analysis of runoff and pollutant washoff in the study area over an extended period of time and addresses the rates of contaminant build-up and antecedent moisture conditions on pollutant loadings and the condition of the receiving stormwater storage facility in terms of water levels and water quality. Continuous simulation addresses contaminant accumulation on streets and determines antecedent moisture conditions for runoff calculations.

The continuous simulation analyses in Calgary have generally been undertaken with the QHM model. QHM is a further development of QUALHYMO, originally developed by A. C. Rowney (U of Ottawa, 1985) and since used across Canada for watershed planning and design studies (DalTech, 1998). The hydrologic concepts in QHM were derived from those in HYMO (Williams and Hahn, 1972), and OTTHYMO (U of Ottawa, 1983). QHM expanded on the capabilities of HYMO and OTTHYMO by including continuous simulation, snow melt, pollutant generation and routing, soil freeze-thaw hydrology, and stream erosion and stream erosion potential.

The hydrologic simulation analysis of this chapter is carried out for the period 1960 to 1997 inclusive. Both snowmelt and rainfall runoff were simulated, utilizing precipitation and temperature data from the Calgary International Airport. The simulation analysis addressed only wet weather loadings, or sediment/pollutant washoff during snowmelt of rainfall events. The analysis did not address dry weather loadings. Dry weather loadings have small magnitudes and long retention times in the sedimentation facility that permanently retains water, and are not considered critical relative to wet weather loadings that are greater in magnitude and will have shorter retention times (Ottawa, 1985). Model parameters were based on detailed calibration analyses undertaken previously (MacKenzie, 1992; MacKenzie, 1988).

\subsubsection{Sedimentation Process}

The sedimentation process used in this analysis is based on the assumption of complete mixing in the sedimentation facility.

Sedimentation can be simulated under conditions equivalent to quiescent settling with no mixing of particles in the vertical plane. All particles move 
uniformly downward at a constant velocity and concentration in the vertical plane is either zero (above the particle which started at the uppermost position in the water column) or constant (below that particle). Sediments remaining in the water flowing from a sedimentation facility under these assumptions are therefore those particles which have a low settling velocity and have not had time to fall past the depth of the outlet structure by the time they have travelled the length of the pond to the outlet end (DalTech, 1998; U of Ottawa, 1985).

The quiescent settling assumption is often used in the design of sedimentation facilities for wastewater treatment and is effective and reasonable if conditions are relatively quiescent or where the particles to settle have relatively high fall velocities.

As an alternate approach, sedimentation can be simulated under conditions equivalent to complete mixing of particles in the vertical plane. Removal of sediments under this assumption can be conceptualized as occurring when individual sediment particles impinge on the bottom of the sedimentation facility without re-suspension. Sediment removal under this assumption is a function of the degree of mixing and time of retention of the sedimentation facility (DalTech, 1998; U of Ottawa, 1985).

The approach adopted in this chapter, through the use of the QHM model, is based on the assumption of complete mixing of particles in the vertical plane. In the development of the QHM model the following rationale was expressed for the adoption of the assumption of complete mixing in the vertical plane (DalTech, 1998; U of Ottawa, 1985).

- The sedimentation facility is likely to experience a high degree of turbulence when subjected to inflows of the magnitude and variability anticipated from stormwater runoff. This makes a quiescent settling assumption questionable and the complete mixing assumption preferable.

- Finer sediment fractions in particular will tend to react more to turbulence and the sedimentation of these fractions may be better approximated under a completely mixed assumption rather than a no vertical mixing assumption. Since the finer sediment fractions may represent a significant portion of the associated pollutants an assumption of complete mixing is preferable.

The vertical mixing assumption used in this analysis will result in a removal rate that decreases as the mass of the sediment in a given vertical section decreases.

In addition to the degree of mixing in the vertical plane in the sedimentation facility, QHM addresses the degree of mixing in the longitudinal horizontal plane 
along the length of the facility. The two extremes of mixing in the longitudinal horizontal plane range from a completely mixed pond, to slug flow with virtually no mixing taking place as the inflow passes through the sedimentation facility as a slug of flow. In this analysis we have considered an interim state, dependent on the final configuration of a sedimentation facility. QHM does not directly address the degree of mixing in the lateral horizontal plane. It is assumed in QHM that the entire width of a facility is available for sedimentation to occur.

\subsection{Street Washoff Particle Size Distribution}

The particle size distribution was based on analysis of Calgary street sweepings undertaken in previous studies (MacKenzie, 1988) and is presented in Table 16.1.

In order to undertake the sedimentation analysis it is necessary to assign settling velocities to each size of sediment addressed in the analysis. The

Table 16.1 Urban sediment washoff particle size distribution.

\begin{tabular}{cc}
\hline Particle Size $(\mu \mathrm{m})$ & $\%$ \\
\hline$>75$ & 89.0 \\
$20-75$ & 5.8 \\
$10-20$ & 1.2 \\
$5-10$ & 1.2 \\
$2-5$ & 1.0 \\
$<2$ & 1.8 \\
\hline
\end{tabular}

question of what constitutes an effective settling velocity is difficult no matter what analytical approach to simulating sedimentation is chosen as the physical situation in the sedimentation facility is not likely to be well represented by the laboratory equipment typically used to measure fall velocities. The effective velocity is represented by the difference between a downward fall velocity and an upward tendency that is a function of turbulence and concentration gradients. As a result the effective fall velocity may not only be less than the discrete settling velocity, but may be time varying as well.

The settling velocities (see Table 16.2) were interpolated from work completed by the Ontario Ministry of Environment and Energy (MOEE, 1994).

Size fractions 1 through 3 will likely settle out in a sedimentation facility. The degree to which they will settle out will be determined by the time available for sedimentation to occur, hence indirectly the size of the sedimentation facility and the flow circulation pattern in the facility. 
Table 16.2 Urban sediment washoff particle size settling velocity.

\begin{tabular}{ccccccl}
\hline \multicolumn{3}{c}{ Size } & \multicolumn{3}{c}{} & $\begin{array}{l}\text { Settling } \\
\text { Velocity } \\
(\mathrm{m} / \mathrm{s})\end{array}$ \\
\hline Fraction & $(\mu \mathrm{m})$ & $(\mathrm{mm})$ & $\%$ & Type & & \\
\hline 1 & $75+$ & $.075+$ & 89.0 & Fine Sand & 0.0005 \\
2 & 45 & .045 & 5.8 & Fine Sand & 0.000025 \\
3 & 15 & .015 & 1.2 & Silt & 0.000008 \\
4 & 7.5 & .0075 & 1.2 & Silt & 0.0000025 \\
5 & 3.5 & .0035 & 2.8 & Clay & 0.0000007 \\
\hline
\end{tabular}

In the approach to simulation of sedimentation discussed herein we have assumed that size fractions 4 and 5 will likely not settle out in a sedimentation facility regardless of the time available for sedimentation. We have assumed that these size fractions are too small to settle and will likely remain in suspension in any sedimentation facility due to their size and considering wind and thermally generated circulation in the facility.

\subsection{Implications of the Street Washoff Particle Size Distribution}

From Table 16.1, it can be seen that some $89 \%$ of the total washoff in any computer simulation will be greater than $75 \mu \mathrm{m}$ in size. The values inTable 16.1 are a composite average of five, post development conditions, street sweeping samples (MacKenzie, 1988).

Past analyses in Calgary have assessed the particle size make up of the bottom sediment collected in a stormwater storage facility in Calgary (Penell, 1983). The study showed that a significant portion of the bottom sediments in the stormwater storage facility were in the gravel size classification, of the order of $20 \mathrm{~mm}$ in diameter. Dependent on the location sampled in the stormwater storage facility the percentage of sediment in the facility in the gravel size range varied from $9 \%$ to $90 \%$, with an average of $33 \%$. The stormwater storage facility bottom sediment sampling results support the washoff results (that large size sediment is washed off streets in rainfall events).

The current stormwater quality enhancement requirements in Calgary are expressed in terms of removal of a percentage of total suspended solids that wash off from a development area. With the high percentage of the potential washoff material in the large $>75 \mu \mathrm{m}$ size range there is the potential for 
disagreement with total suspended solids determined from an in-pipe sampling program and from computer simulation analyses based on washoff calculations.

The most common in-pipe sediment sampling techniques are either grab samples using a sampling container, or an automated tube sampler. The samples may either be point samples in the sewer or depth integrated. However, in either case, the methods only sample the pollutants suspended in the flow (Figure 16.1). A large portion, by mass, of the sediment washoff will not be captured by these sampling techniques. The larger sediment sizes in the pipe system will not be in suspension, but rather 'roll' along the bottom of the pipe, analogous to the concept of bedload (Figure 16.1).

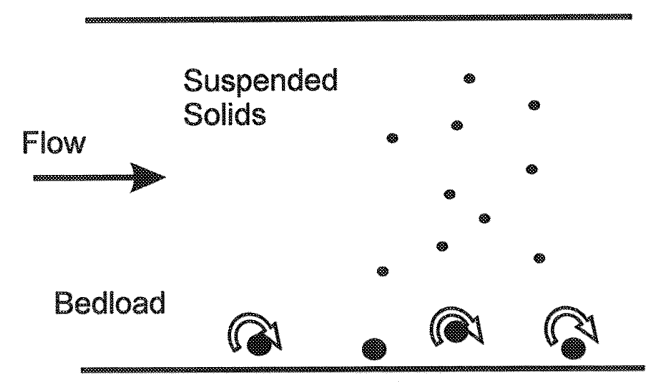

Figure 16.1 Bedload motion.

Stormwater quality enhancement requirements in Calgary are currently formulated as the removal of a given percentage of the total suspended solids that wash off from a new development area. This type of stormwater quality enhancement criteria directly addresses the removal of the mass of stormwater washoff, and indirectly addresses the removal of pollutants that may be adsorbed to individual sediment washoff particles. Despite the characteristic sheen of oil frequently seen on the surface of water lying on the street, such oil is hydrophopic and much is adsorbed by sediments before the water reaches the end of a sewer system. Most metals, including lead, have low solubility in typical surface water, and are rapidly scavenged by sediments. Distribution of phosphorous is extremely variable, but usually no more than $50 \%$ is particulate, with the remainder being either dissolved or colloidal. Most nitrogen is in the dissolved form, with $10 \%$ or less associated with sediments (HydroQual, 1992).

If the objective of the stormwater quality enhancement criteria is the mass removal of sediment washoff, the use of the Calgary street sweeping sampling of Table 16.1 and 16.2 is appropriate. Removal of say $80 \%$ of the sediment 
washoff is directly related to the street sweeping data. However, if the intent of the stormwater quality enhancement criteria is to address pollutant removal using Total Suspended Solids removal as a surrogate, the inclusion of the larger size fractions (currently lumped together as greater than $75 \mu \mathrm{m}$ size classification) in the calculation of TSS may be questionable as a significant or dominant portion of the pollutants adsorbed to street washoff may be associated with the smaller (in the order of $45 \mu \mathrm{m}$ and finer diameter) size fractions (Pettersson, 2002).

A potentially more meaningful representation of TSS based on street washoff is to consider the size fractions that will truly be in suspension as TSS and size fractions that will likely 'roll' along the bottom of the storm sewer system as bed load. For the purposes of this chapter and reflecting the current street washoff size samples adopted for use in Calgary an arbitrary distinction has been adopted of classifying washoff size fraction less than $75 \mu \mathrm{m}$ as TSS and the washoff size fraction greater than $75 \mu \mathrm{m}$ as bed load. Additional monitoring and analyses are required to refine this distinction.

\subsection{Implications of Short-Circuiting in a Stormwater Storage Facility}

Sediment removal in a stormwater storage facility is dependent on the flow path of sediment laden runoff thorough the facility. Current research has demonstrated that the major advective flow in a stormwater pond may occur in a small portion of the cross-section of the facility (short-circuiting) (Shaw et al., 1997). If 'short-circuiting' can occur, the retention time for sediment removal is decreased as the inflow passes through the facility more quickly and the crosssectional area of the facility available for sedimentation is reduced.

Sediment removal in QHM is simulated on the basis of vertical mixing as follows:

$$
L=A R E A *(v s) * C O N C * D E L T
$$

where:

$L=$ sediment removal in a given time step,

$A R E A=$ the horizontal area of stormwater storage facility,

$v s=$ the effective settling velocity of the sediment,

$C O N C=$ concentration during given time step, and

$D E L T=$ time step. 
The effect of the 'short circuiting' on the hydraulic performance of the stormwater storage facility is assessed by considering the full elevation-storage relationship of the stormwater storage facility (split between the four inlets) so as to correctly simulate facility water levels. To more accurately represent the sedimentation capability of the facility considering 'short circuiting', the crosssectional area of the facility must be reduced and the more rapid flow-through addressed.

Under the suggested revised simulation approach the cross-sectional area of the facility is reduced directly by reducing the elevation-surface area relationship of the stormwater storage facility for each inlet. The more rapid flow-through was addressed in an analagous manner by reducing the sedimentation rate for each particle size fraction. The reduced sedimentation rate for each size fraction reflects the shorter flow path available to the particles in suspension and hence the shorter time available for sedimentation.

There are four storm inlets to the stormwater storage facility assessed in this chapter: the northwest inlet, the north inlet, the south inlet and the east inlet (Figure 16.2). The anticipated flow paths for the stormwater storage facility are shown on Figure 16.2. The analysis postulates that 'short-circuiting' will occur for each storm inlet. That is, the full cross-sectional area of the facility will not be available for settling out sediment washoff. The modified sediment/pollutant removal analysis addresses this anticipated operation of the stormwater storage facility.

A pseudo facility was modeled for each storm inlet, defined by its assumed effective flow path length and width (Figure 16.2, Table 16.3).

In order to maintain a realistic simulation of water level fluctuation each pseudo facility was assigned an elevation-storage relationship and elevationdischarge relationship based on assigning the elevation-storage relationship and elevation-discharge for the total stormwater storage facility to each storm inlet on the basis of each storm inlet's contributing catchment area; the effective hydraulics factor of Table 16.3. This approach uses the full capacity of the facility for hydraulic routing and simply apportions the storage volume and discharge capacity of the overall facility, over the depth of the facility, to each pseudo facility on the basis of tributary area. The assumption is felt to be warranted on the basis of consistent land use at each inlet yielding comparable runoff on a unit area basis.

To simulate the reduced cross-sectional area available for sedimentation due to short-circuiting in an individual pseudo facility an effective sedimentation factor was determined for each of the pseudo facilities by dividing the pseudo facility surface area (effective flow length multiplied by the effective flow 


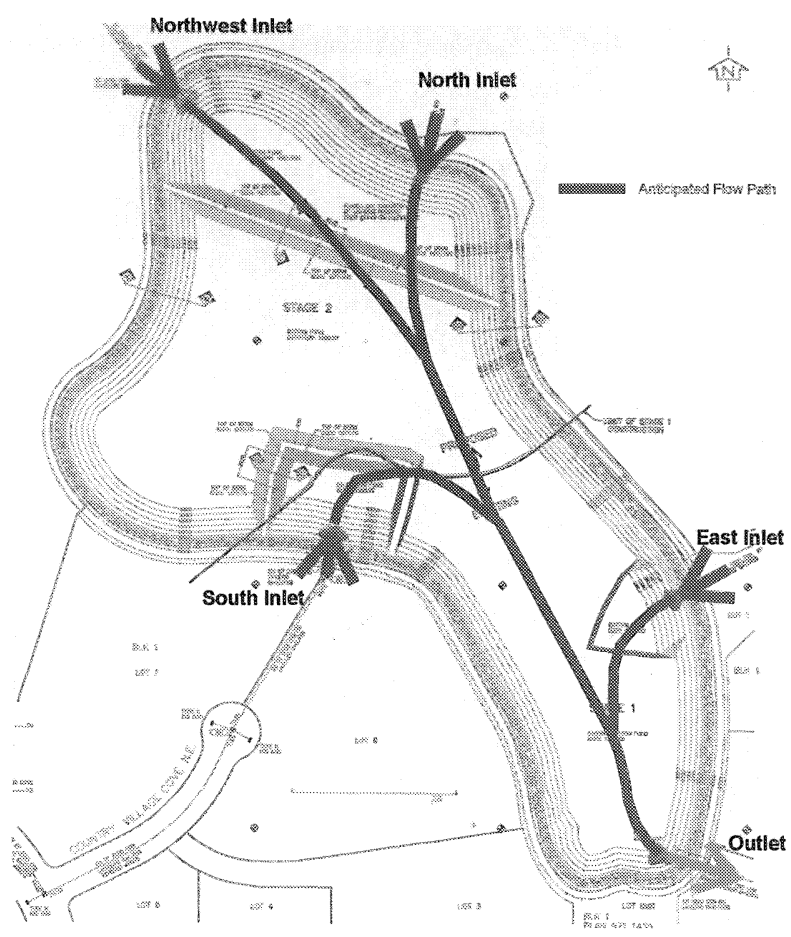

Figure 16.2 Stormwater storage facility.

width) by the overall pond surface area at permanent water level. This factor was applied against the overall pond elevation-surface area relationship over the depth of each pseudo facility to develop a reduced elevation-surface area relationship for each pseudo facility (Table 16.3).

To simulate the reduced time available for sedimentation due to shortcircuiting an equivalent reduction in the sedimentation rates for each washoff size fraction was developed for each pseudo facility. The reduction in sedimentation rates reflects less sedimentation occurring due to the reduction in time available for sedimentation. Sedimentation rates for each pseudo facility were reduced by multiplying the sedimentation rates defined for each size fraction of the washoff by the effective sedimentation factor (Table 16.4).

The QHM computed sediment removal performance was assessed for two conditions: no short-circuiting in the stormwater storage facility, and on the basis of the pseudo ponds described above to represent potential 
Table 16.3 Sedimentation performance hydraulic properties.

\begin{tabular}{|c|c|c|c|c|c|}
\hline \multicolumn{6}{|c|}{ TOTAL STORMWATER STORAGE FACILITY } \\
\hline & $\begin{array}{l}\text { Surface } \\
\text { Area }\end{array}$ & $\begin{array}{l}\text { Storage } \\
\text { Volume }\end{array}$ & \multicolumn{3}{|l|}{ Discharge } \\
\hline Elevation & $\left(\mathrm{m}^{2}\right)$ & $\left(\mathrm{m}^{3}\right)$ & \multicolumn{3}{|l|}{$\left(\mathrm{m}^{3} / \mathrm{s}\right)$} \\
\hline 1069.00 & 45,000 & 0 & \multicolumn{2}{|c|}{ Northwest Catchment Area (ha) } & 170.80 \\
\hline 1069.50 & 50,000 & 19,019 & \multicolumn{2}{|c|}{ North Catchment Area (ha) } & 11.46 \\
\hline 1070.00 & 55,000 & 49,549 & \multicolumn{2}{|c|}{ South Catchment Area (ha) } & 174.53 \\
\hline 1070.50 & 60,000 & 76,541 & \multicolumn{2}{|c|}{ East Catchment Area (ha) } & 32.26 \\
\hline 1071.00 & 65,000 & 76,891 & \multirow{2}{*}{\multicolumn{2}{|c|}{ Total }} & 389.00 \\
\hline 1071.50 & 70,000 & 80,037 & & & \\
\hline 1072.00 & 87,943 & 83,576 & \multicolumn{2}{|l|}{0} & \\
\hline 1072.50 & 91,439 & 101,905 & \multicolumn{2}{|l|}{0.601} & \\
\hline 1073.00 & 94,985 & 121,308 & \multicolumn{2}{|l|}{0.763} & \\
\hline 1073.50 & 98,612 & 154,634 & \multicolumn{2}{|l|}{0.896} & \\
\hline 1074.00 & 114,852 & 164,000 & \multicolumn{2}{|l|}{1.011} & \\
\hline & \multicolumn{3}{|c|}{ NW Pseudo Facility Effective Flow Path (m) } & \multicolumn{2}{|l|}{570} \\
\hline & \multicolumn{3}{|c|}{ NW Pseudo Facility Effective Flow Width (m) } & \multicolumn{2}{|l|}{30} \\
\hline & \multicolumn{3}{|c|}{ NW Pseudo Facility Effective Sedimentation Factor } & \multicolumn{2}{|l|}{0.19} \\
\hline & \multicolumn{3}{|c|}{ North Pseudo Facility Effective Flow Path (m) } & \multicolumn{2}{|l|}{450} \\
\hline & \multicolumn{3}{|c|}{ North Pseudo Facility Effective Flow Path (m) } & \multicolumn{2}{|l|}{30} \\
\hline & \multicolumn{3}{|c|}{ North Pseudo Facility Effective Sedimentation Factor } & \multicolumn{2}{|l|}{0.15} \\
\hline & \multicolumn{3}{|c|}{ South Pseudo Facility Effective Flow Path (m) } & \multicolumn{2}{|l|}{360} \\
\hline & \multicolumn{3}{|c|}{ South Pseudo Facility Effective Flow Width (m) } & \multicolumn{2}{|l|}{10} \\
\hline & \multicolumn{3}{|c|}{ South Pseudo Facility Effective Sedimentation Factor } & \multicolumn{2}{|l|}{0.04} \\
\hline & East Pseudo & o Facility $\mathrm{E}$ & ffective Flow Path (m) & 180 & \\
\hline & East Pseudo & o Facility $\mathrm{E}$ & ffective Flow Width (m) & 15 & \\
\hline & East Pseudo & o Facility $\mathrm{E}$ & ffective Sedimentation Factor & 0.03 & \\
\hline & NW Pseudo & Facility E & ffective Hydraulics Factor & 0.44 & \\
\hline & North Pseu & do Facility & Effective Hydraulics Factor & 0.03 & \\
\hline & South Pseu & do Facility & Effective Hydraulics Factor & 0.45 & \\
\hline & East Pseudo & o Facility $\mathrm{E}$ & ffective Hydraulics Factor & 0.08 & \\
\hline
\end{tabular}


Table 16.3

Table 16.3 Sedimentation performance hydraulic properties cont'd.

\begin{tabular}{|c|c|c|c|c|c|c|c|}
\hline \multicolumn{3}{|c|}{ NW PSEUDO FACILITY } & \multicolumn{5}{|c|}{ NORTH PSEUDO FACILITY } \\
\hline Elevation & $\begin{array}{c}\text { Pseudo } \\
\text { Surface } \\
\text { Area } \\
\left(\mathrm{m}^{2}\right) \\
\end{array}$ & $\begin{array}{c}\text { Pseudo } \\
\text { Storage } \\
\text { Volume } \\
\left(\mathrm{m}^{3}\right) \\
\end{array}$ & $\begin{array}{l}\text { Pseudo } \\
\text { Discharge } \\
\left(\mathrm{m}^{3} / \mathrm{s}\right)\end{array}$ & Elevation & $\begin{array}{c}\text { Pseudo } \\
\text { Surface } \\
\text { Area } \\
\left(\mathrm{m}^{2}\right) \\
\end{array}$ & $\begin{array}{l}\text { Pseudo } \\
\text { Storage } \\
\text { Volume } \\
\left(\mathrm{m}^{3}\right)\end{array}$ & $\begin{array}{l}\text { Pseudo } \\
\text { Discharge } \\
\left(\mathrm{m}^{3} / \mathrm{s}\right)\end{array}$ \\
\hline 1069.00 & 8,550 & 0 & 0 & 1069.00 & 6,750 & 0 & 0 \\
\hline 1069.50 & 9,500 & 8,368 & 0 & 1069.50 & 7,500 & 571 & 0 \\
\hline 1070.00 & 10,450 & 21,802 & 0 & 1070.00 & 8,250 & 1,486 & 0 \\
\hline 1070.50 & 11,400 & 33,678 & 0 & 1070.50 & 9,000 & 2,296 & 0 \\
\hline 1071.00 & 12,350 & 33,832 & 0 & 1071.00 & 9,750 & 2,307 & 0 \\
\hline 1071.50 & 13,300 & 35,216 & 0 & 1071.50 & 10,500 & 2,401 & 0 \\
\hline 1072.00 & 16,709 & 36,773 & 0.000 & 1072.00 & 13,191 & 2,507 & 0.000 \\
\hline 1072.50 & 17,373 & 44,838 & 0.264 & 1072.50 & 13,716 & 3,057 & 0.018 \\
\hline 1073.00 & 18,047 & 53,376 & 0.336 & 1073.00 & 14,248 & 3,639 & 0.023 \\
\hline 1073.50 & 18,736 & 68,039 & 0.394 & 1073.50 & 14,792 & 4,639 & 0.027 \\
\hline 1074.00 & 21,822 & 72,160 & 45 & 1074.00 & 17,228 & 4,920 & 0.030 \\
\hline \multicolumn{4}{|c|}{ SOUTH PSEUDO FACILITY } & \multicolumn{4}{|c|}{ EAST PSEUDO FACILITY } \\
\hline Elevation & $\begin{array}{l}\text { Pseudo } \\
\text { Surface } \\
\text { Area } \\
\left(\mathrm{m}^{2}\right) \\
\end{array}$ & $\begin{array}{c}\text { Pseudo } \\
\text { Storage } \\
\text { Volume } \\
\left(\mathrm{m}^{3}\right.\end{array}$ & $\begin{array}{c}\text { Pseudo } \\
\text { Discharge } \\
\left(\mathrm{m}^{3} / \mathrm{s}\right)\end{array}$ & Elevation & $\begin{array}{c}\text { Pseudo } \\
\text { Surface } \\
\text { Area } \\
\left(\mathrm{m}^{2}\right)\end{array}$ & $\begin{array}{c}\text { Pseudo } \\
\text { Storage } \\
\text { Volume } \\
\left(\mathrm{m}^{3}\right)\end{array}$ & $\begin{array}{c}\text { Pseudo } \\
\text { Discharge } \\
\left(\mathrm{m}^{3} / \mathrm{s}\right)\end{array}$ \\
\hline 1069.00 & 1,800 & 0 & 0 & 1069.00 & 1,350 & 0 & 0 \\
\hline 1069.50 & 2,000 & 8,559 & 0 & 1069.50 & 1,500 & 1,522 & 0 \\
\hline 1070.00 & 2,200 & 22,297 & 0 & 1070.00 & 1,650 & 3,964 & 0 \\
\hline 1070.50 & 2,400 & 34,443 & 0 & 1070.50 & 1,800 & 6,123 & 0 \\
\hline 1071.00 & 2,600 & 34,601 & 0 & 1071.00 & 1,950 & 6,151 & 0 \\
\hline 1071.50 & 2,800 & 36,017 & 0 & 1071.50 & 2,100 & 6,403 & 0 \\
\hline 1072.00 & 3,518 & 37,609 & 0.000 & 1072.00 & 2,638 & 6,686 & 0.000 \\
\hline 1072.50 & 3,658 & 45,857 & 0.270 & 1072.50 & 2,743 & 8,152 & 0.048 \\
\hline 1073.00 & 3,799 & 54,589 & 0.343 & 1073.00 & 2,850 & 9,705 & 0.061 \\
\hline 1073.50 & 3,944 & 69,585 & 0.403 & 1073.50 & 2,958 & 12,371 & 0.072 \\
\hline 1074.00 & 4,594 & 73,800 & 0.455 & 1074.00 & 3,446 & 13,120 & 0.081 \\
\hline
\end{tabular}

Notes: (1) Pseudo pond surface area determined from Effective Flow Path and Effective Length/Width Ratio.

(2) Pseudo Pond Storage and Pseudo Pond Discharge determined from Effective Hydraulics Factor 
Table 16.4 Sedimentation performance settling velocities.

\begin{tabular}{|c|c|c|c|c|c|c|}
\hline \multicolumn{4}{|c|}{$\begin{array}{l}\text { NW Pseudo Pond Effective Sedimentation Factor } \\
\text { North Pseudo Pond Effective Sedimentation Factor }\end{array}$} & $\begin{array}{l}0.19 \\
0.15\end{array}$ & & \\
\hline \multicolumn{4}{|c|}{ South Pseudo Pond Effective Sedimentation Factor } & 0.04 & & \\
\hline \multicolumn{4}{|c|}{ South Pseudo Pond Effective Sedimentation Factor } & 0.03 & & \\
\hline \multicolumn{7}{|c|}{ Particle Size Settling Velocity } \\
\hline & & & $\begin{array}{l}\text { NorthWest } \\
\text { Pseudo Pond }\end{array}$ & $\begin{array}{c}\text { North } \\
\text { Pseudo Pond }\end{array}$ & $\begin{array}{l}\text { South } \\
\text { Pseudo Pond }\end{array}$ & $\begin{array}{c}\text { East } \\
\text { Pseudo Pond }\end{array}$ \\
\hline Fraction & $\begin{array}{l}\text { Size } \\
(\mu \mathrm{m})\end{array}$ & $\begin{array}{c}\text { Settling } \\
\text { Velocity } \\
(\mathrm{m} / \mathrm{s})\end{array}$ & $\begin{array}{l}\text { Pseudo Settling } \\
\text { Velocity }(\mathrm{m} / \mathrm{s})\end{array}$ & $\begin{array}{l}\text { Pseudo } \\
\text { Settling } \\
\text { Velocity } \\
(\mathrm{m} / \mathrm{s})\end{array}$ & $\begin{array}{l}\text { Pseudo } \\
\text { Settling } \\
\text { Velocity } \\
(\mathrm{m} / \mathrm{s})\end{array}$ & $\begin{array}{l}\text { Pseudo } \\
\text { Settling } \\
\text { Velocity } \\
(\mathrm{m} / \mathrm{s})\end{array}$ \\
\hline 1 & $75+$ & 0.0005 & 0.000097 & 0.000077 & 0.00002 & 0.000015 \\
\hline 2 & 45 & 0.000025 & 0.0000049 & 0.0000038 & 0.000001 & 0.0000008 \\
\hline 3 & 15 & 0.000008 & 0.0000016 & 0.0000012 & 0.0000003 & 0.0000002 \\
\hline 4 & 7.5 & 0.0000025 & 0.00000049 & 0.00000038 & 0.0000001 & 0.00000008 \\
\hline 5 & 3.5 & 0.0000007 & 0.000000136 & 0.000000107 & 0.000000029 & 0.000000021 \\
\hline
\end{tabular}

short-circuiting in the facility. Anticipated sediment removal performance without considering short-circuiting in the stormwater storage facility is presented in Table 16.5, and anticipated performance considering shortcircuiting is presented in Table 16.6 .

A comparison of the two anticipated sediment removals is presented below. The comparison is based on the assumed split between bedload washoff and TSS washoff at the $75 \mu \mathrm{m}$ size fraction. A different definition of bedload versus TSS washoff may yield different results. The intent here is to present a suggested computational technique, not absolute results.

Anticipated sediment removal is compared under three classifications:

- Bedload removal:

different bedload removal is anticipated: $90 \%$ versus $100 \%$

- TSS removal including bedload: different TSS removal including bedload removal is anticipated: $84 \%$ versus $96 \%$

- TSS removal excluding bedload:

quite different TSS removal excluding bedload is anticipated: $34 \%$ versus $61 \%$

The importance of considering the effects of short-circuiting in the stormwater storage facility is dependent on the definition of the performance criteria of the facility. If the performance criteria are stipulated such that total 
Table 16.5 Anticipated sediment removal - single facility.

\begin{tabular}{|c|c|c|c|c|}
\hline \multirow{2}{*}{$\begin{array}{l}\text { Size } \\
\text { Fraction }\end{array}$} & \multirow{2}{*}{$\begin{array}{r}\text { Size } \\
(\mu \mathrm{m})\end{array}$} & \multirow{2}{*}{$\begin{array}{c}\text { Sediment Generated } \\
(\mathrm{kg})\end{array}$} & \multicolumn{2}{|c|}{ Sediment Removed } \\
\hline & & & Fraction & Mass (kg) \\
\hline 1 & $75+$ & $22,500,000$ & 1.000 & $22,500,000$ \\
\hline 2 & 45 & $1,470,000$ & 0.974 & $1,431,780$ \\
\hline 3 & 15 & 304,000 & 0.924 & 280,896 \\
\hline 4 & 7.5 & 304,000 & 0.000 & 0 \\
\hline 5 & 3.5 & 709,000 & 0.000 & 0 \\
\hline \multicolumn{5}{|c|}{ Total Sediment Generated (kg) } \\
\hline & & (size fractions $1-5$ ) & $25,287,000$ & \\
\hline & & & $2,787,000$ & \\
\hline \multicolumn{5}{|c|}{ Total Sediment Removed $(\mathrm{kg})$} \\
\hline & & (size fractions $1-3$ ) & $24,212,676$ & \\
\hline \multicolumn{5}{|c|}{ (size fractions $2-3$ ) } \\
\hline & \multicolumn{4}{|c|}{ Percentage Removal } \\
\hline & \multicolumn{2}{|c|}{ Bedload Removal (75+ um) } & $100 \%$ & \\
\hline & \multicolumn{4}{|c|}{ Total Suspended Solids Removal } \\
\hline & & (including bedload) & $96 \%$ & \\
\hline & & (excluding bedload) & $61 \%$ & \\
\hline
\end{tabular}

sediment removal is of importance, the effect of short-circuiting on the assessment of the facility may be significant ( $84 \%$ removal versus $96 \%$ removal). However, if the performance criteria are stipulated such that perhaps nutrient removal is of interest, expressed as TSS removal as a surrogate, then removal of the finer size fractions may be paramount. In this case the effect of short-circuiting on the assessment of the facility may be quite significant $(34 \%$ versus $61 \%$ ) considering TSS as size fractions $<75 \mu \mathrm{m}$. A more striking potential difference is indicated if TSS removal based on size fractions $<75 \mu \mathrm{m}$, considering short-circuiting, is compared to the current practice of considering TSS based on all size fractions and no short-circuiting (34\% versus $96 \%$ ).

\subsection{Future Analyses}

The discussion in this chapter is based on analyses undertaken to date for the assessment of the stormwater quality enhancement performance of a stormwater storage facility in Calgary. The assessment of the potential effects on stormwater quality enhancement of short-circuiting in the stormwater storage facility was based on a subjective, intuitive, definition of anticipated flow paths and resultant mixing in the stormwater storage facility. 
Table 16.6 Anticipated sediment removal - multiple pseudo ponds.

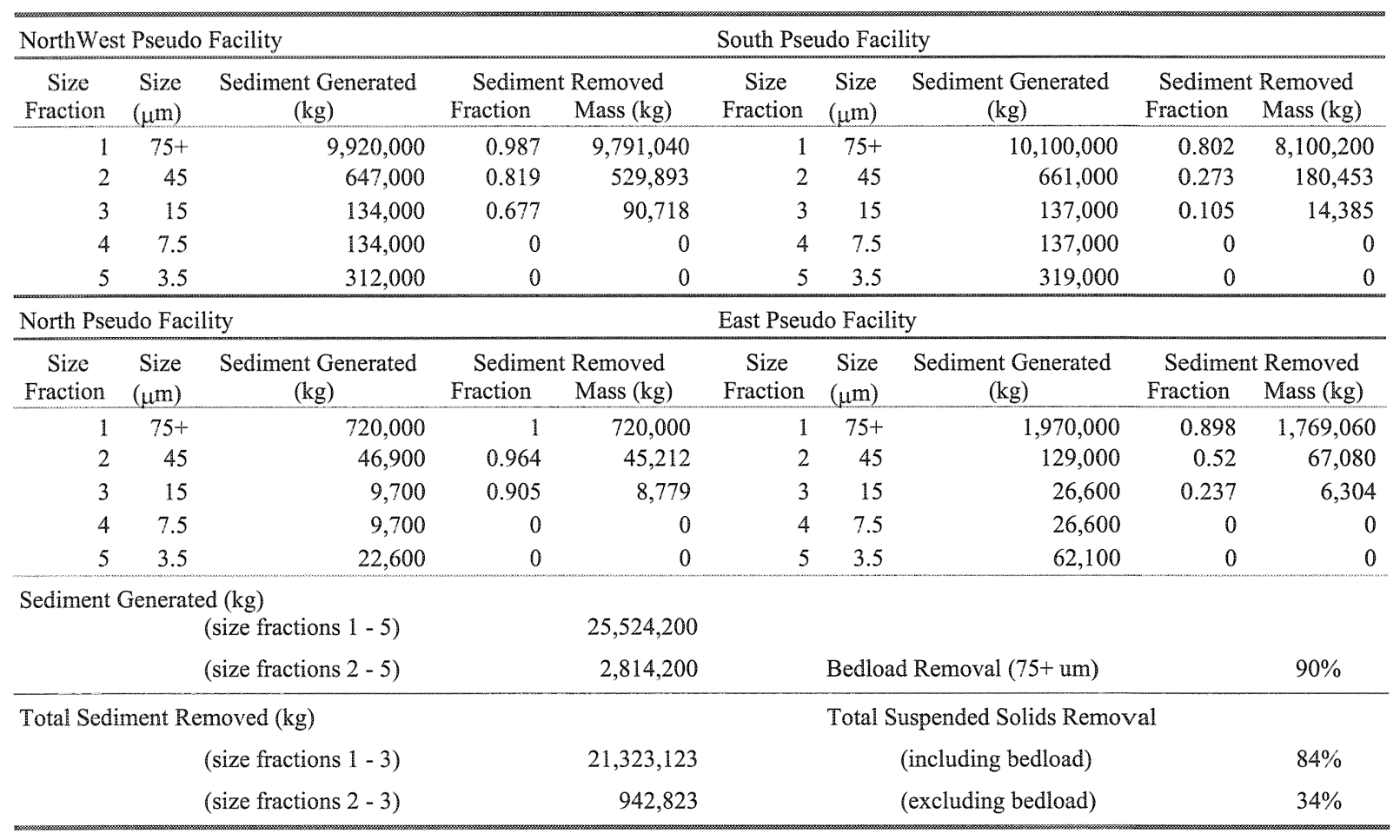


Work has now begun on a finite element analysis of the stormwater storage facility. This research work, financed by the City of Calgary, will define flow paths and mixing in the stormwater storage facility addressed in this chapter. The results of the finite element analysis will be used to more accurately define the expected flow paths in the stormwater storage facility and to revise the subjective definition of flow paths.

\subsection{Conclusions}

This chapter presents a review and summary of the technical approach used in Calgary for assessing the degree of sediment removal from urban runoff by stormwater storage facilities.

A classification of washoff from urban development as bedload and total suspended solids (TSS) has been presented. Size fractions in the washoff greater than $75 \mu \mathrm{m}$ have been considered to be bedload, likely 'rolling' along the bottom of storm pipes rather than suspended in flow.

A suggested modification to the inputs to QHM to address potential shortcircuiting in stormwater storage facilities through the partition of the facility into a number of pseudo ponds is made. To simulate the hydraulic performance of an overall stormwater storage facility (water levels) the full elevation-storage and elevation-discharge relationship for the overall facility (split between the inlets of the facility) was used. Each pseudo pond was assigned an elevationstorage and elevation-discharge relationship determined by assigning a portion of the overall elevation-storage and elevation-discharge relationship on the basis of each pseudo pond storm inlet tributary area.

To represent the sedimentation performance for each pseudo pond considering short-circuiting, the elevation-surface area and the sedimentation rates were reduced on the basis of the ratio of each pseudo pond surface area to the overall pond surface area.

In assessing the results of the simulation of sedimentation by QHM, washoff to the facility smaller than $10 \mu \mathrm{m}$ was considered not to settle out in the facility regardless of QHM results. It is suggested that this size washoff is too small to settle out and will remain in suspension due to wind and thermally generated circulation effects in the stormwater storage facility. 


\section{References}

DalTech, 1998. QHM Version 2.0 User's Manual and Technical Notes. Centre for Water Resources studies. DalTech University. Halifax, Nova Scotia. January, 1998.

HydroQual, 1992. Assessment of City of Calgary 1989 - 1990 Runoff Water Quality Database for Outfalls G13 and G18. HydroQual Consultants Inc. Calgary, Alberta. May, 1992.

MacKenzie, J.N.,1988. Strathcona Development Area Sediment Control Analysis Technical Support Study. JNMacKenzie Engineering Ltd. Calgary, Alberta. August, 1988.

MacKenzie, J.N., 1992. The Glenmore Reservoir Stormwater Quality Improvement Study. A Report to the City of Calgary. JNMacKenzie Engineering Ltd. Calgary, Alberta. May, 1992.

MOEE, 1994. Stormwater Management Practices Planning and Design Manual. Ontario Ministry of Environment and Energy. Queen's printer for Ontario. Toronto, Ontario. June, 1994.

Penell, 1983. Report on Subsoil Conditions and Classification Tests on Storm Sewer Sediment Deposit 68 Street and 17 Avenue SE Calgary, Alberta. Penell Geotechnical Engineering Ltd. December, 1983.

Pettersson, 2002. Characteristics of Suspended Particles in a Small Stormwater Pond. Thomas J. R. Pettersson. 9th International Conference on Urban Drainage - Global Solutions for Urban Drainage. Portland, Oregon. September, 2002.

Shaw et al, 1997. Flow Pattern Characterization in an Urban Stormwater Detention Pond and Implications for Water Quality. J.K.E. Shaw, W.E. Watt, J.Marsalek, B.B. Anderson and A.A. Crowder. Water Quality Research Journal of Canada, Volume 32, No. 1, 53-71. 1997.

U of Ottawa, 1983. Improved Stormwater Management (IMPSWMM) Urban Drainage Modeling Procedures. University of Ottawa. Ottawa, Ontario. September, 1983.

U of Ottawa, 1985. QUALHYMO User's Manual. A. C. Rowney and P. E. Wisner. University of Ottawa. Ottawa, Ontario. September, 1985.

Williams and Hahn, 1972. HYMO, A problem Oriented Computer Language for Hydrologic Modeling. User's Manual. U.S. Department of Agriculture. May, 1972. 
